\title{
Incidence and immunochemical features of serum cryoglobulin in chronic liver disease
}

\author{
G. P. JORI, G. BUONANNO, F. D'ONOFRIO,1 A. TIRELLI, \\ F. GONNELLA, AND S. GENTILE \\ From the Institute of Medical Pathology, 1st Medical Faculty, University of Naples, and the \\ Haematological Division, Ospedale S. Gennaro, Naples, Italy
}

SUMMARY Essential cryoglobulinaemia was detected in 44 out of 150 patients $(29 \%)$ screened on the basis of histological confirmation of chronic inflammatory liver disease (chronic persistent or aggressive hepatitis, or cirrhosis). Cryoglobulinaemia prevailed in the patients whose hepatic tissue showed more features of active inflammation; also, a female prevalence was observed. There were no correlations between cryoglobulinaemia and either HBsAg positivity or alcoholic liver disease. Mixed cryoglobulins made of heterogeneous immunoglobulins without monotypic components were mostly associated with established cirrhosis, whereas monotypic cryoglobulins were exclusively found in patients with either persistent or aggressive chronic hepatitis. Mixed cryoglobulins with a monotypic component were associated with all histological grades of liver damage. This study affords an objective evaluation of both the frequency and immunochemical features of cryoglobulins associated with chronic inflammatory liver disease.

Although essential cryoglobulinaemia has been repeatedly documented in patients with chronic liver disease (Jori and Buonanno, 1972; Eliakim et al., 1972; Florin-Christensen et al., 1974), the frequency of this clinical association is not precisely known. On the other hand, although refined immunochemical analysis of serum cryoglobulins has been systematically performed in a large series of patients with either immunoproliferative or autoimmune disorders (Brouet et al., 1974), similar data have been produced only for a small number of patients with chronic liver disease (Florin-Christensen et al., 1974). Thus, the present study has sought to provide a basis for assessing these points. Attempts have also been made to correlate essential cryoglobulinaemia with both histological classification and recognisable aetiology of hepatic disease.

\section{Methods}

\section{PATIENTS}

This study was planned to determine the frequency of essential cryoglobulinaemia among 150 patients, 75 males and 75 females, screened by histological

${ }^{1}$ Address for reprint requests: Professor Felice D'Onofrio, Istituto di Patologia Medica, Piazza Miraglia, 80138 Napoli, Italia.

Received for publication 18 August 1976 evidence of chronic inflammatory liver disedse. All the patients taken into consideration were hospitalised at our institutions between January 1970 and August 1975. The initial selection of patients was made on the basis of clinical and/or biochemical findings suggestive of hepatic impairment; further steps included histological confirmation of chronic liver disease (chronic persistent or aggressive hepatitis, or cirrhosis) and search for serum cryoglobulin. Patients positive for both features were subsequently submitted to full clinical investigation, in order to exclude malignant proliferative diseases, chronic infections, and autoimmune disorders. Finally, patients with chronic liver disease either associated or unassociated with essential cryoglobulinaemia were admitted into the present series until completion of both the male and the female groups.

\section{LIVER STUDIES}

Since histological confirmation of chronic inflammatory liver disease was a prerequisite for patients admission into this study, a liver biopsy was performed in each patient by means of either the Menghini or the Vim-Silvermann needles. All the biopsy specimens were routinely stained with both haematoxylin and eosin and the Gordon-Sweet method for reticulin fibres. All the histological 
diagnoses were made by the same pathologist, who was requested to retain for this study only these biopsy specimens which could be unequivocally classified into one of the following categories: chronic hepatitis, either persistent or aggressive, inactive cirrhosis and cirrhosis with active hepatitis, according to standard criteria (Scheuer, 1973). Additional mention was made of pathological lesions attributable to alcoholism, such as fatty change, centrilobular hepatitis, Mallory's hyalin and micronodular cirrhosis. Other hepatic disorders and doubtful cases were discarded; no cases of primary biliary cirrhosis were found among our patients.

Besides routine laboratory investigations, both radioimmunoassay (RIA) and counter-immunoelectrophoresis (CIEP) were done for HBsAg in all patients. Careful recording was made of drug intake and/or alcohol abuse. In this last regard, it should be noted that both history of alcohol abuse and consistent pathological findings were requested for the diagnosis of alcoholic liver disease.

\section{ISOLATION AND PURIFICATION OF}

CRYOGLOBULINS

Twenty millilitres of venous blood were collected without anticoagulant from the fasting patient by means of plastic syringes kept at $37^{\circ} \mathrm{C}$. The blood was allowed to clot for three hours in a water bath at $37^{\circ} \mathrm{C}$ and thereafter centrifuged at $37^{\circ} \mathrm{C}$. The serum was transferred into narrow tubes and kept at temperatures between $0^{\circ}$ and $4^{\circ} \mathrm{C}$ until the eighth day. No precipitation occurred in normal sera submitted to these procedures, whereas the narrow tubes allowed easy detection of minute amounts of cryoprecipitate. The cryoprecipitate was resuspended in cold normal saline and purified by five centrifugations and washings at $4^{\circ} \mathrm{C}$, the first one being followed by redissolution of the cryoprecipitate at $37^{\circ} \mathrm{C}$. In all cases, the amounts of serum cryoglobulin were assessed by measuring ultraviolet absorption at $280 \mathrm{~m} \mu$ of an aliquot of the cryoprecipitate dissolved in acetic acid $1 \mathrm{M}$. When the amount of the cryoglobulin was appreciable, it was also evaluated by comparing the serum protein level before and after cryoprecipitation. The purified cryoprecipitate was characterised by electrophoresis and immunoelectrophoresis against both antihuman total sera and monospecific antiserums to gamma, alpha, and mu chains. The immunoglobulin present in the cryoprecipitate was classified as monotypic by typing of light chains, either by immunoelectrophoresis or by double diffusion analysis in gel.

In order to compare them with the biological and clinical study of Brouet et al. (1974), the purified cryoglobulins were classified into three groups, by slight modification of the criteria suggested by
Klein et al. (1972): type I, monotypic cryoglobulins made of immunoglobulins with only one class or sub-class of light chains; type II, mixed cryoglobulins with a monotypic component, made of immunoglobulins belonging to two different classes, one of which is monotypic; and type III, mixed cryoglobulins made of heterogeneous immunoglobulins belonging to two or more classes.

\section{Results}

As shown in Table 1, pure cryoglobulins were detected in the sera of 44 out of 150 patients $(29 \%)$ with histologically confirmed chronic inflammatory liver disease and without other underlying disorders possibly leading to altered immunoglobulin synthesis. According to histological classification of liver disease, the higher incidence of cryoglobulin positives was found among patients with chronic aggressive hepatitis $(43.5 \%)$, whereas incidence of $38 \%$, $36.6 \%$, and $9.4 \%$, respectively, were recorded among patients with chronic persistent hepatitis, cirrhosis with active hepatitis, and in those with inactive cirrhosis. In the whole series, cryoglobulinaemia was more frequent in females ( 28 out of $75,37 \cdot 3 \%$ ) than in males ( 16 out of $75,21 \cdot 3 \%$ ). Although this female prevalence is not statistically significant, it was observed in cirrhosis with active hepatitis $(40 \%$ of females versus $21.3 \%$ of males), in chronic aggressive hepatitis $(46.6 \%$ of females versus $37.5 \%$ of males), and in chronic persistent hepatitis $(41.7 \%$ of females versus $33.3 \%$ of males), whereas in inactive cirrhosis cryoglobulinaemia slightly prevailed in male patients ( $10 \%$ of males versus $7.6 \%$ of females).

The cryoglobulin positive females were aged 34 to 70 years, mean 57 ; the males 30 to 68 years, mean 54.

Table 2 shows that no correlations were found between cryoglobulinaemia and either $\mathrm{HBsAg}$ positivity or alcoholic liver disease. Thus, lack of recognisable causes of liver damage was more often present in cryoglobulin positive patients $(75 \%)$ than in the negative ones $(47 \%)$. In no instance was sufficient evidence found to warrant the possibility of drug-induced hepatitis.

As shown in Table 3, immunochemical analysis of the 44 positive sera revealed a general prevalence of the mixed cryoglobulins type III (20 patients) followed by monotypic cryoglobulins type I (14 patients) and mixed cryoglobulins with a monotypic component type II (10 patients). Among type I cryoglobulins, the IgM cryoglobulin was the one most frequently detected, whereas the IgA (kappa) cryoglobulin was found in a single instance. In 10 patients out of 14 the serum level of type I cryoglobulin was greater than $1 \mathrm{mg} / \mathrm{ml}$. Among type II 
Table 1 Incidence of essential cryoglobulinaemia in 150 patients ( 75 males and 75 females) with chronic liver disease

\begin{tabular}{|c|c|c|c|c|c|c|c|c|}
\hline \multirow[t]{3}{*}{ Histological diagnosis } & \multicolumn{2}{|c|}{ Sex } & \multicolumn{6}{|c|}{ Cryoglobulin positives } \\
\hline & \multirow[t]{2}{*}{$M$} & \multirow[t]{2}{*}{$F$} & \multicolumn{2}{|l|}{ Total } & \multicolumn{2}{|c|}{ Males } & \multicolumn{2}{|c|}{ Females } \\
\hline & & & No. & $\%$ & No. & $\%$ & No. & $\%$ \\
\hline $\begin{array}{l}\text { Chronic persistent hepatitis (21) } \\
\text { Cirrhosis with inactive disease (53) } \\
\text { Chronic aggressive hepatitis (46) } \\
\text { Cirrhosis with active hepatitis (30) } \\
\text { Total (150) }\end{array}$ & $\begin{array}{r}9 \\
40 \\
16 \\
10 \\
75\end{array}$ & $\begin{array}{l}12 \\
13 \\
30 \\
20 \\
75\end{array}$ & $\begin{array}{l}8 / 21 \\
5 / 53 \\
20 / 46 \\
11 / 30 \\
44 / 150\end{array}$ & $\begin{array}{c}38 \\
9 \cdot 4 \\
43 \cdot 5 \\
36 \cdot 6 \\
29\end{array}$ & $\begin{array}{c}3 / 9 \\
4 / 40 \\
6 / 16 \\
3 / 10 \\
16 / 75\end{array}$ & $\begin{array}{l}33 \cdot 3 \\
10 \\
37 \cdot 5 \\
21 \cdot 3 \\
21 \cdot 3\end{array}$ & $\begin{array}{r}5 / 12 \\
1 / 13 \\
14 / 30 \\
8 / 20 \\
28 / 75\end{array}$ & $\begin{array}{r}41 \cdot 7 \\
7 \cdot 6 \\
46 \cdot 6 \\
40 \\
37 \cdot 3\end{array}$ \\
\hline
\end{tabular}

Table 2 Aetiology of chronic liver disease in 150 patients either positive or negative for essential cryoglobulinaemia

\begin{tabular}{llll}
\hline & \multicolumn{2}{c}{ Frequency (\%) } \\
\cline { 2 - 4 } Aetiology of chronic liver disease & $\begin{array}{l}\text { General frequency (\%) } \\
(150)\end{array}$ & $\begin{array}{l}\text { Cryoglobulin } \\
\text { positive (44) }\end{array}$ & $\begin{array}{l}\text { Cryoglobulin negative } \\
(106)\end{array}$ \\
\hline Viral (both RIA and CIEP) & 14 & 9 & 16 \\
Alcoholic (both history and pathological lesions) & 30.7 & 16 & 37 \\
Undetermined & 55.3 & 75 & 47 \\
\hline
\end{tabular}

Number of patients in parentheses.

Table 3 Immunochemical classification and serum levels of the 44 cryoglobulins

\begin{tabular}{|c|c|c|c|c|}
\hline \multirow[t]{2}{*}{ Type of cryoglobulin } & \multirow{2}{*}{$\begin{array}{l}\text { Immunochemical } \\
\text { analysis }\end{array}$} & \multicolumn{3}{|c|}{ Cryoglobulin level $(\mathrm{mg} / \mathrm{ml})$} \\
\hline & & $<1$ & $1-5$ & $>5$ \\
\hline Type I, monotypic cryoglobulin (14) & $\begin{array}{l}\operatorname{IgM} 9 / 14 \\
\operatorname{IgG~} 4 / 14 \\
\operatorname{IgA} 1 / 14\end{array}$ & $4 / 14$ & $6 / 14$ & $4 / 14$ \\
\hline Type II, mixed cryoglobulins with a monotypic component (10) & $\begin{array}{l}\text { IgM-IgG } 9 / 10 \\
\text { IgG-IgG } 1 / 10\end{array}$ & $5 / 10$ & $3 / 10$ & $2 / 10$ \\
\hline Type III, mixed cryoglobulins (20) & $\begin{array}{l}\text { IgM-IgG } 17 / 20 \\
\text { IgM-IgG-IgA } 3 / 20\end{array}$ & $18 / 20$ & $2 / 20$ & $\mathbf{0}$ \\
\hline
\end{tabular}

Number of patients in parentheses.

cryoglobulins, the IgM-IgG variety was by far the most frequently isolated one, since only in a single instance was an IgG-IgG cryoglobulin detected in our series. The monotypic component of the IgMIgG cryoglobulins was an IgM kappa protein in all cases but one, in which a lambda light chain was found. In five cases out of 10 the serum levels of type II cryoglobulins were lower than $1 \mathrm{mg} / \mathrm{ml}$; however, in two patients serum levels of 6 and 11 $\mathrm{mg} / \mathrm{ml}$, respectively, were found. Among type III cryoglobulins there was an impressive prevalence of the IgM-IgG variety, since only in three cases was an IgM-IgG-IgA cryoglobulin detected. The serum level of these heterogeneous cryoglobulins was usually very low $(0.2$ to $1.3 \mathrm{mg} / \mathrm{ml})$.

According to histological diagnosis of liver disease (Table 4) $75 \%$ and $25 \%$ of patients with chronic persistent hepatitis had, respectively, type I and type II cryoglobulins; $40 \%, 25 \%$, and $35 \%$ of patients with chronic aggressive hepatitis had, respectively, type I, type II, and type III cryoglobulins; $20 \%$ and $80 \%$ of patients with inactive cirrhosis had, respectively, type II and type III cryoglobulins; and $18 \%$ and $82 \%$ of patients with active cirrhosis had, respectively, type II and type III cryoglobulins.

Of interest is the fact that vascular purpura, Raynaud's phenomenon, and arthralgia were additional features transiently observed in about $50 \%$ of our cryoglobulinaemic patients. Thus, vascular purpura of the lower limbs was more frequent among patients with either type II (seven out of 10) or type III (14 out of 20) than in those with type I cryoglobulin (three out of 14). In no instance did the purpura rashes appear to be enhanced by cold sensitivity. On the other hand, mild Raynaud's phenomenon was evenly distributed among all cryoglobulin types (type I, six patients out of 14; type II, five out of 10; and type III 12 out of 20). It should be noted that neither skin necrosis nor major vascular injuries were observed among our patients. Finally, arthralgia prevailed among patients with either type III (14 out of 20) or type II cryoglobulins (six out of 10), whereas minor articular manifestations were alleged by three out of 14 patients with type I cryoglobulin. 
Table 4 Distribution of 44 cryoglobulins according to histological classification of liver disease

\begin{tabular}{|c|c|c|c|c|c|c|}
\hline \multirow[t]{3}{*}{ Histological classification of liver disease } & \multicolumn{6}{|c|}{ Immunochemical type of cryoglobulin } \\
\hline & \multicolumn{2}{|l|}{$\boldsymbol{I}$} & \multicolumn{2}{|l|}{$\boldsymbol{I I}$} & \multicolumn{2}{|l|}{ III } \\
\hline & No. & $\%$ & No. & $\%$ & No. & $\%$ \\
\hline $\begin{array}{l}\text { Chronic persistent hepatitis (8) } \\
\text { Chronic aggressive hepatitis (20) } \\
\text { Cirrhosis with inactive disease (5) } \\
\text { Cirrhosis with active hepatitis (11) }\end{array}$ & $\begin{array}{l}6 / 8 \\
8 / 20 \\
0 \\
0\end{array}$ & $\begin{array}{l}75 \\
40\end{array}$ & $\begin{array}{l}2 / 8 \\
5 / 20 \\
1 / 5 \\
2 / 11\end{array}$ & $\begin{array}{l}25 \\
25 \\
20 \\
18\end{array}$ & $\begin{array}{l}0 \\
7 / 20 \\
4 / 5 \\
9 / 11\end{array}$ & $\begin{array}{l}35 \\
80 \\
82\end{array}$ \\
\hline
\end{tabular}

Number of patients in parentheses.

\section{Discussion}

This study suggests that cryoglobulinaemia can be detected in about one-third of patients with chronic inflammatory liver disease unassociated with other conditions possibly leading to altered immunoglobulin synthesis. Although our group's interest in cryoglobulinaemia has probably caused a preselected referral of patients complaining of purpura and arthralgia, it should be noted that Druet et al. (1973) found serum cryoglobulins in $70 \%$ of cirrhotic patients with glomerulonephritis and in $21.7 \%$ of cirrhotics without renal disease. Thus, it is possible that racial factors account for the high incidence of the cryoglobulin-associated syndrome in some geographical areas.

In our series a good correlation was found between the degree of inflammatory activity in the hepatic tissue and the incidence of cryoglobulinaemia; also, cryoglobulinaemia was prevalent in females. However, it should be noted that this female prevalence, although impressive, is not statistically significant.

Both HBsAg positivity and evidence of alcoholic liver disease were more often obtained in cryoglobulin-negative than in cryoglobulin-positive patients. Thus, neither viral infection nor alcohol abuse seem to play a significant role in causing cryoglobulinaemia associated with chronic liver disease.

In the present study, the purified cryoglobulins were grouped into three categories, by slight modification of the criteria previously suggested by Klein et al. (1972). Although the biological significance of this classification requires further evaluation, its value in establishing correlations between the biological findings and the clinical features as well as the underlying diseases (Brouet et al., 1974) might be supported by our data.

Thus, type I monotypic cryoglobulins, the serum levels of which ranged from very low to considerably high, were mostly found in patients with chronic persistent hepatitis and, to a lesser degree, in those with aggressive hepatitis. In no instance was type I cryoglobulin detected in a cirrhotic patient. Type II mixed cryoglobulins with a monotypic component were more frequently detected among patients with chronic hepatitis, either persistent or aggressive, than in those with established cirrhosis; their serum level was usually very low, although in some cases it was greater than $5 \mathrm{mg} / \mathrm{ml}$. Type III mixed cryoglobulins were mostly found in cirrhotic patients; their serum level was usually very low. Both vascular purpura and arthralgia prevailed among patients with either type II or type III cryoglobulins, whereas mild Raynaud's phenomenon, not leading to fingertip ulceration or gangrene, was evenly distributed among patients with all cryoglobulin types. Since the detection of mixed IgG-IgG cryoglobulins is often very difficult (Brouet et al., 1974), it is possible that we have overestimated the frequency of monotypic IgG cryoglobulins in our series.

Other clinical features of the cryoglobulinassociated syndrome have been previously described (Jori and Buonanno, 1972). In the course of the present study six cryoglobulinaemic patients with active cirrhosis developed either membranous or proliferative glomerulonephritis, eventually leading to terminal uraemia. Two of these cases have been reported elsewhere (Valente et al., 1972). Other immunopathic diseases were not observed in our series.

The possibility of correlations between presence or absence of cryoglobulins and non-organ specific autoimmune markers is worthy of interest. Preliminary data from our laboratory (D'Onofrio et al., unpublished results) show a high incidence of antinuclear antibodies, positive LE-cell tests, and smooth muscle antibodies in cryoglobulinaemic patients with chronic active liver disease (CALD). However, the significance of this association is difficult to assess. A controlled study of treatments and early prognosis of the cryoglobulin-associated syndrome is in progress at our institutions.

As stated in a recent review (Summerskill, 1974), the clinical association of cryoglobulinaemia with CALD has practical importance; however, the relationship between cryoglobulinaemia and liver disease is not clear. Since this clinical study affords objective data on both the incidence and immunochemical characteristics of cryoglobulins in CALD, 
it might contribute to the elucidation of this problem.

The authors wish to thank Dr W. H. J. Summerskill for helpful advice and criticism in preparing this manuscript.

\section{References}

Brouet, J. C., Clauvel, J. P., Danon, F., Klein, M., and Seligmann, M. (1974). Biologic and clinical significance of cryoglobulins. A report of 86 cases. American Journal of Medicine, 57, 775-788.

Druet, P., Letonturier, P., Contet, A., and Mandet, C. (1973). Cryoglobulinaemia in human renal disease. A study of seventy-six cases. Clinical and Experimental Immunology, 15, 483-496.

Eliakim, M., Zlotnick, A., and Slavin, S. (1972). Gammopathy in liver disease. In Progress in Liver Disease, vol. 4, pp. 410-417. Edited by H. Popper and F. Schaffner. Grune and Stratton: New York.

Florin-Christensen, A., Roux, M. E. B., and Arana, R. M. (1974). Cryoglobulins in acute and chronic liver disease. Clinical and Experimental Immunology, 16, 599-605.

Jori, G. P., and Buonanno, G. (1972). Chronic hepatitis and cirrhosis of the liver in cryoglobulinaemia. Gut, 13, 610613.

Klein, M., Danon, F., Brouet, J. C., Signoret, Y., and Seligmann, M. (1972). Étude immunochimique de 130 cryoglobulines humaines. Revuet Européenne d'Études Cliniques et Biologiques, 17, 948-957.

Scheuer, P. J. (1973). Liver Biopsy Interpretation, 2nd edn., pp. 66-86. Baillière Tindall: London.

Summerskill, W. H. J. (1974). Chronic active liver disease reexamined: prognosis hopeful. Gastroenterology, 66, 450464.

Valente, A., Volpe, E., Jori, G. P., and Buonanno, G. (1972). Renal disease in essential cryoglobulinaemia. Italian Journal of Immunology and Immunopathology, 3, 75-87. 